\title{
BMJ Effect of low-protein diet on kidney Open function in diabetic nephropathy: meta-analysis of randomised controlled trials
}

\author{
Uru Nezu, ${ }^{1}$ Hiroshi Kamiyama, ${ }^{2}$ Yoshinobu Kondo, ${ }^{3}$ Mio Sakuma, ${ }^{4}$ \\ Takeshi Morimoto, ${ }^{4}$ Shinichiro Ueda ${ }^{1}$
}

To cite: Nezu U,

Kamiyama $\mathrm{H}$, Kondo $\mathrm{Y}$, et al. Effect of low-protein diet on kidney function in diabetic nephropathy:

meta-analysis of randomised controlled trials. BMJ Open 2013;3:e002934.

doi:10.1136/bmjopen-2013002934

- Prepublication history and additional material for this paper are available online. To view these files please visit the journal online (http://dx.doi.org/10.1136/ bmjopen-2013-002934).

Received 25 March 2013 Accepted 25 April 2013

This final article is available for use under the terms of the Creative Commons Attribution Non-Commercial 2.0 Licence; see http://bmjopen.bmj.com

For numbered affiliations see end of article.

Correspondence to Dr Shinichiro Ueda; blessyou@med.u-ryukyu.ac.jp

\section{ABSTRACT}

Objective: To evaluate the effect of low-protein diet on kidney function in patients with diabetic nephropathy.

Design: A systematic review and a meta-analysis of randomised controlled trials.

Data sources: MEDLINE, EMBASE, Cochrane Library, ClinicalTrials.gov, International Standard Randomised Controlled Trial Number (ISRCTN) Register and University Hospital Medical Information Network-Clinical Trials Registry (UMIN-CTR) from inception to 10 December 2012. Internet searches were also carried out with general search engines (Google and Google Scholar).

Study selection: Randomised controlled trials that compared low-protein diet versus control diet and assessed the effects on kidney function, proteinuria, glycaemic control or nutritional status.

Primary and secondary outcome measures and data synthesis: The primary outcome was a change in the glomerular filtration rate (GFR). The secondary outcomes were changes in proteinuria, post-treatment value of glycated haemoglobin A1C (HbA1C) and posttreatment value of serum albumin. The results were summarised as the mean difference for continuous outcomes and pooled by the random effects model. Subgroup analyses and sensitivity analyses were conducted regarding patient characteristics, intervention period, methodological quality and assessment of diet compliance. The assessment of diet compliance was performed based on the actual protein intake ratio (APIR) of the low-protein diet group to the control group.

Results: We identified 13 randomised controlled trials enrolling 779 patients. A low-protein diet was associated with a significant improvement in GFR $(5.82 \mathrm{ml} / \mathrm{min} /$ $1.73 \mathrm{~m}^{2}, 95 \% \mathrm{Cl} 2.30$ to $9.33, \mathrm{I}^{2}=92 \%$; $n=624$ ). This effect was consistent across the subgroups of type of diabetes, stages of nephropathy and intervention period. However, GFR was improved only when diet compliance was fair $\left(8.92,95 \% \mathrm{Cl} 2.75\right.$ to $15.09, \mathrm{I}^{2}=92 \%$ for APIR $<0.9$ and $0.03,95 \% \mathrm{Cl}-1.49$ to $1.56, \mathrm{I}^{2}=90 \%$ for APIR $\geq 0.9$ ). Proteinuria and serum albumin were not differed between the groups. HbA1c was slightly but significantly decreased in the low-protein diet group $(-0.26 \%, 95 \% \mathrm{Cl}$ -0.35 to $-0.18, I^{2}=0 \% ; n=536$ ).

\section{ARTICLE SUMMARY}

Article focus

- Our research question is whether low-protein diet treatment is beneficial or not in patients with diabetic nephropathy.

- Our hypothesis was that low-protein diet improves kidney function, but this effect is affected by patients' actual compliance with diet treatment.

Key messages

- A low-protein diet significantly improved kidney function in patients with diabetic nephropathy.

- This effectiveness was observed only when patients' diet compliance was fair; however, the successful treatment may not need to be as stringent as the current clinical guidelines recommend.

Strengths and limitations of this study

- Unique and reasonable approach to minimise the bias by interstudy difference in patients' compliance with diet treatment.

- Quality of the evidence was not high when assessed by the Grading of Recommendations, Assessment, Development and Evaluation (GRADE) approach.

- A few missing data were imputed, generating a risk of heterogeneity.

Conclusions: Low-protein diet was significantly associated with improvement of diabetic nephropathy. The adverse effects of low-protein diet were not apparent such as worsening of glycaemic control and malnutrition.

\section{INTRODUCTION}

Diabetic nephropathy is the leading cause of end-stage renal disease necessitating renal replacement therapy ${ }^{12}$ and is also associated with increased risk of cardiovascular 
mortality. ${ }^{3}$ It affects up to $40 \%$ of diabetic patients ${ }^{4}$ and the medical cost for treatment piles up to US $\$ 16.8$ billion in the USA and US $\$ 1.2$ billion in the UK each year. ${ }^{5}$

The progression of diabetic nephropathy can be slowed down by optimal glycaemic control ${ }^{167}$ and that of blood pressure control by renin-angiotensin system blockade. ${ }^{89}$ As for the diet therapy, a low-protein diet (LPD) is recommended in clinical guidelines by the American Diabetes Association. ${ }^{10}{ }^{11}$ This is based on animal studies and several small studies on humans. However, previously conducted randomised controlled trials (RCTs) have not consistently shown the benefits of LPD.

To elucidate this clinical question, several meta-analyses have been published on this topic. ${ }^{12-14}$ However, some of them included pre-post study and crossover trials which might have obscured the pure effect of intervention. In addition, RCTs of diet treatment have always been facing the difficulty of achieving sufficient compliance. In this view, we conducted a meta-analysis considering the interstudy variance of diet compliance with an additional study involving a considerable number of patients subsequently published. ${ }^{15}$

\section{METHODS}

We carried out meta-analysis in accordance with the Preferred Reporting Items for Systematic Reviews and Meta-Analysis (PRISMA) Statement for systematic reviews and meta-analyses. ${ }^{16}$

\section{Search strategy}

We searched RCTs via PubMed, EMBASE, Cochrane Library, ClinicalTrials.gov, International Standard Randomised Controlled Trial Number (ISRCTN) Register and University Hospital Medical Information Network-Clinical Trials Registry (UMIN-CTR) from inception to 10 December 2012 to identify relevant citations. Internet searches were also carried out with general search engines (such as Google and Google Scholar). Studies written in English evaluating the effect of LPD comparing with control diet among diabetic patients were identified using the search terms 'protein restriction' OR 'low protein diet' AND ‘diabetes'.

\section{Study selection}

We assessed all the identified studies for the criteria of this meta-analysis. Two independent investigators (UN and HK) sorted out the potentially relevant studies first by title and abstract review, and finally judged the eligibility by full-text review. When discrepancies occurred, we discussed in a committee involving four investigators of our research group (UN, MS, TM and SU).

Inclusion criteria are as follows: published in full text, RCTs with a parallel design of LPD among patients with either type 1 diabetes mellitus (T1DM) or type 2 diabetes mellitus (T2DM) and any of the following outcomes are available; glomerular filtration rate (GFR), creatine clearance $(\mathrm{CCr})$, proteinuria, albuminuria, glycated haemoglobin A1C (HbAlc) or serum albumin. RCTs of crossover design were excluded because of the possible carryover effect. As for the studies likely to have multiple reports, we selected the most recent publication after assessing their independency focusing on the patients' background, intervention details, outcome settings and the results.

\section{Data extraction}

We extracted data related to published year, number of patients and their characteristics (age, gender, duration of diabetes mellitus and stages of diabetes nephropathy), details of the prescribed diet, intervention period. Also, we extracted data for patients' compliance by integrating the data on actual protein intake $(\mathrm{g} / \mathrm{kg} /$ day, $\mathrm{g} /$ day, $\mathrm{mg} /$ mg or energy per cent) evaluated in each study, then calculated the LPD to control ratio of actual protein intake (APIR). We utilised these results to assess study quality and subsequent subgroup analyses.

As primary outcome data, we extracted the mean change in GFR $\left(\mathrm{ml} / \mathrm{min} / 1.73 \mathrm{~m}^{2}\right)$ or $\mathrm{CCr}(\mathrm{ml} / \mathrm{min} /$ $1.73 \mathrm{~m}^{2}$ ) from baseline to the end of the diet intervention. As the secondary outcome, we extracted the mean change in proteinuria $(\mathrm{g} / 24 \mathrm{~h})$, albuminuria $(\mathrm{mg} / 24 \mathrm{~h}, \mu \mathrm{g} / \mathrm{min})$, urine albumin to creatine ratio $(\mathrm{Cre}, \mathrm{mg} / \mathrm{mmol}$ ), posttreatment value of HbAlc (\%) and post-treatment value of serum albumin $(\mathrm{g} / \mathrm{dl})$. Different digit numbers of proteinuria $(\mathrm{mg} / 24 \mathrm{~h})$ and albuminuria $(\mathrm{g} / 24 \mathrm{~h})$ were converted to fit the above scales.

We unified the notation for nephropathy stage into three ways; normoalbuminuria, microalbuminuria (incipient nephropathy) and macroalbuminuria (overt nephropathy).The value of HbAlc (\%) extracted from Japanese articles was converted from Japan Diabetes Society (JDS) to National Glycohemoglobin Standardization Program (NGSP) by an equation announced by JDS as NGSP (\%) $=1.02 \times$ JDS $(\%)+0.25 \% .^{17}$

\section{Risk of bias assessment}

Using the Cochrane Collaboration's 'risk of bias' tool, ${ }^{18}$ we assessed the risk of bias of included studies. We assessed seven domains: (1) sequence generation, (2) allocation concealment, (3) blinding of participants and personnel, (4) blinding of outcome assessment, (5) incomplete outcome data, (6) selective outcome reporting and (7) other bias by patients' diet compliance. Since this study aimed to investigate the clinical effect of dietary intervention which encourages patients' lifestyle modification, we considered that patients' diet compliance was the most critical factor to generate risk of bias. Therefore, we categorised studies with APIR over 0.9 as 'high risk'.

Next, we scored the risk level of each domain from 0 to 2; high risk $=2$, unclear risk $=1$ and low risk $=0$. As an exception, we gave a score of 3 to 'high risk' of 'other bias by diet compliance' to lay more weight on this 
domain. Finally, we assessed the included studies' overall risk of bias by the total score of the seven domains.

\section{Quantitative data synthesis}

We summarised results as the mean difference of continuous variables with $95 \%$ CIs and combined data by means of a random effects model with inverse variance weighting. GFR and CCr were used interchangeably, since it is commonly used as an estimate of GFR. Since proteinuria and albuminuria were measured in different measurements and scales, we used the standardised mean difference by dividing the mean value by the SD.

If SDs were missing, we obtained them by converting from alternative variance measures such as SEs, CIs and $p$ values. When even such information was not available, we imputed the value using a technique by Follmann $e t a l^{19}$ and Abrams et al..$^{20}$ This technique utilises the correlation coefficient obtained from a study giving detailed information.

We subsequently conducted subgroup analyses for the main outcomes. Prespecified subgroups were based on the patients' baseline characteristics (body mass index (BMI), type of diabetes and stages of diabetic nephropathy) and study methodology (intervention period, measurement index of proteinuria, overall assessment risk of bias and diet compliance assessed by APIR).

We used $\mathrm{I}^{2}$ statistics to assess statistical heterogeneity among studies. The possible publication bias was assessed by visual asymmetry of a funnel plot. We referred to the Cochrane Handbook V.5.1.0 ${ }^{18}$ for methodological guidance. We used Review Manager (RevMan) for Windows Software V.5.1.7 (the Nordic Cochrane Centre, Copenhagen, Denmark).

\section{Quality of evidence}

We graded the quality of evidence for the primary outcome using the Grading of Recommendations,
Assessment, Development and Evaluation (GRADE) approach $^{21}{ }^{22}$ using GRADEpro software V.3.6 (for Windows; Jan Brozek, Andrew Oxman, Holger Schünemann, 2008). The quality of the evidence for GFR was low (see online supplementary table A).

\section{RESULTS}

\section{Search results}

As shown in figure 1, we initially obtained 912 records through electrical database search. Eight hundred and sixty-four were excluded after evaluation of titles and abstracts. After removing 27 duplicates, we selected 21 fulltext articles for detailed assessment for eligibility. Among these, we excluded eight studies: one study owing to lack of comparison, ${ }^{23}$ two studies of non-randomisation trial $^{2425}$ and three studies of crossover design. ${ }^{26-28}$ In addition, we excluded two studies which were likely to have multiple reports published by the same author group. ${ }^{29} 30$ We included the recent publication in analyses. Similarly, two studies by Pijls et al were likely to have multiple reports. However, we did not exclude the previous publication, since only that provided the postintervention value of HbAlc, the secondary outcome in our meta-analysis. Finally, we included 13 RCTs reporting the effects of LPD in diabetic patients. ${ }^{15} 31-42$

\section{Characteristics of included studies}

The included studies evaluated the effects of LPD in 779 diabetic patients (209 T1DM and 555 T2DM) from Japan, ${ }^{15}$ Mexico, ${ }^{31}$ France, ${ }^{32}$ Italy, ${ }^{33}$ Australia, ${ }^{34}$ Denmark, ${ }^{35}$ Netherlands, ${ }^{36}{ }^{37}{ }^{39}$ South Africa, ${ }^{38}$ Italy $^{41}$ and the USA. ${ }^{40}{ }^{42}$ Study patients were middle-aged men and women, mostly obese or overweight (table 1). Mean duration of diabetes history was 18 years. T1DM accounted for six studies and T2DM for five studies. Two studies included both T1DM and T2DM patients and
Figure 1 Flow diagram of the process for study selection.
912 records identified through database searching

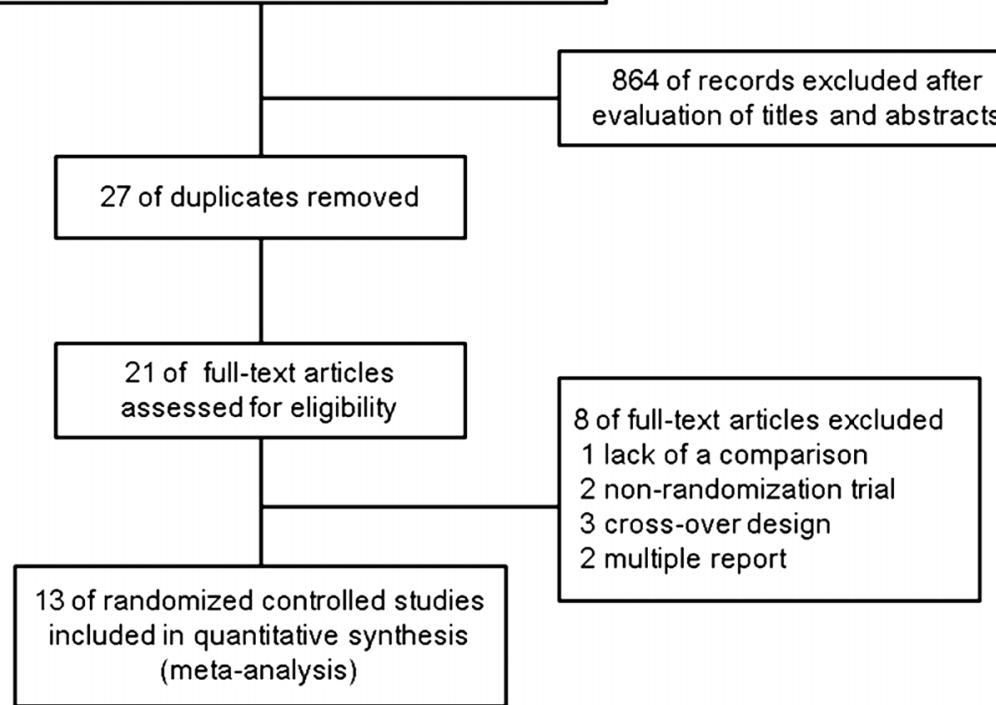


provided no separate information. The stage of diabetic nephropathy ranged from normoalbuminuria to macroalbuminuria. Eight studies provided distinct information generated from a single nephropathy stage; however, the remaining five studies reported only the combined results of two neighbour stages. Baseline GFR was $76 \mathrm{ml} / \mathrm{min} / 1.73 \mathrm{~m}^{2}$ and HbAlc was $8.3 \%$ in average. An intervention period ranged from 3 to 60 months (18 months in median). All trials clarified random assignment and the methods were generally adequate (see online supplementary figure $\mathrm{A}$ and table $\mathrm{B}$ ). However, allocation concealment was unclear in about half of the studies. With regards to blinding of intervention, only one study ${ }^{31}$ applied single-blind method. Although the outcome assessment was not blinded to the assessors in any of the studies, the risk of bias is considered to be small since the outcome is objective. Attrition bias was seen in variety. We considered the proportion in the number of incomplete patients and the reasons for dropping out, in order to see whether these were different across the intervention groups. Although selective reporting was not concerned, other biases by insufficient diet compliance were considered in four studies as we describe later.

\section{Diet prescription and compliance assessment}

Table 2 shows the details of diet prescription and compliance assessment. The prescribed protein level was $0.6-0.8 \mathrm{~g} / \mathrm{kg} /$ day in LPD and $1.0-1.6 \mathrm{~g} / \mathrm{kg} /$ day in control. In five studies, patients in the control diet treatment group were instructed to continue their habitual diet instead of setting any numerical goal of protein intake. $335-3739$

Diet compliance was assessed in all trials. Ten studies measured $24 \mathrm{~h}$ urine urea nitrogen ( $24 \mathrm{~h}$ UUN) and calculated daily protein intake $(\mathrm{g} / \mathrm{kg} /$ day $) .{ }^{15} \quad 31-33 \quad 35-40$ They used Maroni's formula, the gold standard of protein intake estimation considering nitrogen loss from a non-urine source. ${ }^{43}{ }^{44}$ One study by Ben et al reported only the value of $24 \mathrm{UUN}$ (g/day) without using this formula. ${ }^{42}$ Nine studies conducted additional or alternative assessment, such as spot UUN to Cre (UUN/Cre), ${ }^{34}$ $4 \mathrm{~h} \mathrm{UUN},{ }^{41}$ food questionnaire, food record or recall technique. $^{15} 31-333739$

APIR ranged from 0.44 to 1.07 . When setting the cut-off value of APIR for sufficient compliance as 0.9 , it was less than 0.9 in only nine studies (69.2\%). Interestingly, all of the T1DM studies showed fair compliance (APIR <0.9). ${ }^{35}{ }^{38-42}$ However, only two out of five T2DM31 34 study achieved fair diet compliance. ${ }^{31} 34$ Two studies including both T1DM and T2DM patients showed values of 1.07 and 0.69 , respectively. ${ }^{32} 33$

\section{Effects of LPD on kidney function}

Eleven trials of 624 patients provided the change in kidney function assessed either by GFR or CCr. GFR was significantly increased by $5.82 \mathrm{ml} / \mathrm{min} / 1.73 \mathrm{~m} 2$ after LPD (95\% CI 2.30 to $9.33 \mathrm{ml} / \mathrm{min} / 1.73 \mathrm{~m} 2$; figure 2).
We found a significant heterogeneity across the studies $\left(\mathrm{I}^{2}=92 \%, \mathrm{p}<0.00001\right)$; however, the funnel plot showed no major asymmetricity (see online supplementary figure D).

\section{Effects of LPD on proteinuria}

Twelve studies of 634 patients provided sufficient information regarding change in proteinuria. ${ }^{15} \quad 31-36 \quad 38-42$ The standard mean difference showed no significant change in proteinuria after LPD $(-0.14,95 \%$ CI -0.74 to $0.46 ; p=0.65$; figure 3 ). Although we found heterogeneity across the studies $\left(I^{2}=91 \%, p<0.00001\right)$, the funnel plot showed no major asymmetricity (see online supplementary figure E).

\section{Effects of LPD on glycaemic control}

Glycaemic control was assessed by the absolute value of HbAlc after diet treatment. In eleven studies which provided sufficient information, HbA1c was slightly but significantly decreased after LPD $(-0.26 \%, 95 \%$ CI -0.35 to -0.18 ; see online supplementary figure B). Although we found heterogeneity across the studies $\left(\mathrm{I}^{2}=0 \%\right.$, $\mathrm{p}<0.00001)$, the funnel plot showed no major asymmetricity (see online supplementary figure F).

\section{Effects of LPD on nutritional status}

Nutritional status was assessed by the absolute value of serum albumin after diet treatment. Only four studies of 179 patients provided sufficient information. ${ }^{32} 333839$ As a result, serum albumin was not changed after LPD $(-0.18,95 \%$ CI -0.53 to $0.17, p=0.32$; see online supplementary figure $\mathrm{C})$. Heterogeneity between trials was significant $\left(\mathrm{I}^{2}=88 \%, \mathrm{p}<0.00001\right)$, and the funnel plot showed asymmetrical appearance (see online supplementary figure $\mathrm{G})$.

\section{Subgroup and sensitivity analyses}

Table 3 shows subgroup analysis according to clinical characteristics and study quality. There were significant differences in change in GFR between the subgroups based on nephropathy stage $(p=0.03)$ and diet compliance $(p=0.006)$. Specifically, GFR was improved in the subgroup of macroalbuminuria and subgroup of fair diet compliance (APIR <0.9). There was no significant difference between subgroups of BMI, type of diabetes, overall risk of bias and diet compliance. As for the change in proteinuria, there were significant differences between the subgroups of BMI $(p<0.0001)$, type of diabetes $(p=0.002)$, nephropathy stage $(p=0.001)$ and measurement index of proteinuria $(\mathrm{p}<0.00001)$. There was no significant difference between the subgroups of intervention period, overall risk of bias and diet compliance. The post-treatment value of HbAlc was not differed across the subgroups. As for serum albumin, the sensitivity analysis excluding only one study by Dussol et al, which showed poor diet compliance (APIR 1.02), showed no significant change after LPD $(-0.25,95 \%$ CI -0.64 to $0.15 ; p=0.22, I^{2}=91 \%$, data not shown in table). 
Table 1 Characteristics of included studies

\begin{tabular}{|c|c|c|c|c|c|c|c|c|c|c|}
\hline Author (year) & Subjects (n) & Male (n) & Age (years) & BMI $\left(\mathrm{kg} / \mathrm{m}^{2}\right)$ & $\begin{array}{l}\text { Type of } \\
\text { diabetes }\end{array}$ & $\begin{array}{l}\text { Duration of } \\
\text { diabetes } \\
\text { (years) }\end{array}$ & $\begin{array}{l}\text { Nephropathy } \\
\text { stage }\end{array}$ & $\begin{array}{l}\text { GFR }(\mathrm{ml} / \mathrm{min} / \\
\left.1.73 \mathrm{~m}^{2}\right)\end{array}$ & $\begin{array}{l}\text { HbA1c } \\
(\%)\end{array}$ & $\begin{array}{l}\text { Intervention } \\
\text { period } \\
\text { (months) }\end{array}$ \\
\hline Koya (2009) & 112 & 59 & 57 & 24.6 & $\mathrm{~T} 2$ & - & Macroalbuminuria & 62 & 8.1 & 60 \\
\hline Velázquez (2008) & 60 & 40 & 67 & 27.7 & T2 & 17 & $\begin{array}{l}\text { Normoalbuminuria, } \\
\text { microalbuminuria } \\
\text { or } \\
\text { macroalbuminuria }\end{array}$ & 55 & 8.3 & 4 \\
\hline Dussol (2005) & 47 & 83 & 52 & - & Mixed & 15 & $\begin{array}{l}\text { Microalbuminuria } \\
\text { or } \\
\text { macroalbuminuria }\end{array}$ & 38 & 8.1 & 24 \\
\hline Meloni (2004) & 80 & 48 & 55 & - & Mixed & 17 & Macroalbuminuria & 100 & 7.0 & 12 \\
\hline Brinkworth (2004) & 38 & 39 & 62 & 33.5 & T2 & - & $\begin{array}{l}\text { Normoalbuminuria } \\
\text { or } \\
\text { microalbuminuria }\end{array}$ & - & 6.4 & 3 \\
\hline Hansen (2002) & 72 & 65 & 41 & 25.0 & T1 & 28 & Macroalbuminuria & 62 & 9.8 & 48 \\
\hline Pijls (2002) & 131 & 58 & 66 & 27.8 & T2 & 7 & $\begin{array}{l}\text { Normoalbuminuria } \\
\text { or } \\
\text { microalbuminuria }\end{array}$ & 86 & 7.7 & 28 \\
\hline Pijls (1999) & 121 & 61 & 63 & 27.7 & T2 & 7 & $\begin{array}{l}\text { Normoalbuminuria } \\
\text { or } \\
\text { microalbuminuria }\end{array}$ & 82 & 7.7 & 12 \\
\hline Raal (1994) & 22 & 36 & 30 & 24.9 & T1 & 20 & Macroalbuminuria & 84 & 13.0 & 6 \\
\hline Dullaart (1993) & 30 & 90 & 41 & 24.1 & T1 & 23 & Microalbuminuria & 68 & 7.8 & 24 \\
\hline Zeller (1991) & 35 & 60 & 34 & - & T1 & 22 & Macroalbuminuria & 126 & 7.9 & 35 \\
\hline Brouhard (1990) & 15 & 9 & 33 & - & T1 & 19 & $\begin{array}{l}\text { Microalbuminuria } \\
\text { or } \\
\text { macroalbuminuria }\end{array}$ & 47 & 7.3 & 12 \\
\hline Ciavarella (1987) & 16 & 56 & 37 & - & $\mathrm{T} 1$ & 18 & Macroalbuminuria & 100 & 8.9 & 4.5 \\
\hline
\end{tabular}

BMI, body mass index; GFR, glomerular filtration rate; HbA1c, haemoglobin A1C; T1, type 1; T2, type 2. 
Table 2 Details of diet prescription and compliance assessment

\begin{tabular}{|c|c|c|c|c|c|c|c|c|c|}
\hline \multirow[b]{2}{*}{ Author (year) } & \multicolumn{2}{|l|}{ LPD } & \multicolumn{2}{|l|}{ Control } & \multicolumn{2}{|c|}{$\begin{array}{l}\text { Actual protein } \\
\text { intake based on } \\
24 \mathrm{~h} \mathrm{UUN}^{*}\end{array}$} & \multicolumn{3}{|c|}{$\begin{array}{l}\text { Actual protein intake based on alternative } \\
\text { methods* }\end{array}$} \\
\hline & $\begin{array}{l}\text { Subjects } \\
\text { (n) }\end{array}$ & Prescription* & $\begin{array}{l}\text { Subjects } \\
\text { (n) }\end{array}$ & Prescription* & $\begin{array}{l}\text { LPD vs } \\
\text { control* }^{*}\end{array}$ & APIR & Method & LPD vs control* & APIR \\
\hline Koya (2009) & 56 & 0.8 & 56 & 1.2 & 1.0 vs 1.0 & 1.0 & FR & 0.9 vs 1.1 & - \\
\hline Velázquez (2008) & 29 & $0.6-0.8$ & 31 & $1.0-1.2$ & 0.82 vs 1.2 & 0.68 & RT (24 h) & 56.0 vs 80.7 (g/day) & - \\
\hline Dussol (2005) & 22 & 0.8 & 25 & 1.2 & 1.10 vs 1.03 & 1.07 & $\mathrm{FQ}$ & 68 vs 84 (g/day) & - \\
\hline Meloni (2004) & 40 & 0.8 & 40 & Free & 0.86 vs 1.24 & 0.69 & $\mathrm{FQ}$ & 0.86 vs 1.24 & - \\
\hline Brinkworth (2004) & 19 & $\begin{array}{l}15 \% \text { of energy } \\
\text { from protein }\end{array}$ & 19 & $\begin{array}{l}30 \% \text { of energy from } \\
\text { protein }\end{array}$ & - & - & UUN/Cre & 35.6 vs $42.9(\mathrm{mg} / \mathrm{mg})$ & 0.8 \\
\hline Hansen (2002) & 38 & 0.6 & 34 & As usual & 0.89 vs 1.02 & 0.87 & - & - & - \\
\hline Pijls (2002) & 63 & 0.8 & 68 & As usual & 1.1 vs 1.14 & 0.96 & - & - & - \\
\hline Pijls (1999) & 58 & 0.8 & 63 & As usual & 1.12 vs 1.15 & 0.97 & $\mathrm{FQ}$ & 0.93 vs 1.12 & - \\
\hline Raal (1994) & 11 & 0.8 & 11 & 1.6 & 0.87 vs 2.0 & 0.44 & $\mathrm{FQ}$ & value not described & - \\
\hline Dullaart (1993) & 14 & 0.6 & 16 & As usual & 0.79 vs 1.09 & 0.72 & $\begin{array}{l}\mathrm{RT} \\
\text { (1 week) }\end{array}$ & $\begin{array}{l}\text { Animal protein, } 5 \text { vs } 10 \\
\text { (energy \%) } \\
\text { Vegetable protein, } 6 \text { vs } 6 \\
\text { (energy \%) }\end{array}$ & - \\
\hline Zeller (1991) & 20 & 0.6 & 15 & $>1.0$ & 0.72 vs 1.08 & 0.67 & - & - & - \\
\hline Brouhard (1990) & 8 & 0.6 & 7 & As usual & - & - & $24 \mathrm{~h}$ UUN & 5.8 vs 9.8 (g/day) & 0.6 \\
\hline Ciavarella (1987) & 7 & 0.71 & 9 & 1.44 & - & - & $4 \mathrm{~h}$ UUN & 0.8 vs 1.44 & 0.6 \\
\hline
\end{tabular}

*Units: $\mathrm{g} / \mathrm{kg} /$ day unless specified.

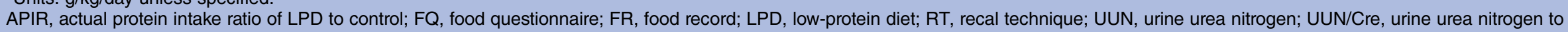
creatine ratio. 


\begin{tabular}{|c|c|c|c|c|c|c|c|c|c|}
\hline Study or Subgroup & \multicolumn{3}{|c|}{ Experimental } & \multicolumn{3}{|c|}{ Control } & \multicolumn{2}{|c|}{$\begin{array}{c}\text { Mean Difference } \\
\text { Weight IV, Random, } 95 \% \mathrm{Cl}\end{array}$} & $\begin{array}{l}\text { Mean Difference } \\
\text { IV, Random, } 95 \% \mathrm{Cl}\end{array}$ \\
\hline Koya. 2009 & -21.4 & 22.8 & 56 & -20.3 & 20 & 56 & $7.1 \%$ & $-1.10[-9.04,6.84]$ & - \\
\hline Veláquez, 2008 & & & & & & & & & \\
\hline normoalbuminuria & -1.3 & 5.1 & 9 & -2.9 & 3.5 & 10 & $9.7 \%$ & $1.60[-2.38,5.58]$ & 7 \\
\hline microalbuminuria & 6.5 & 9 & 10 & -7.3 & 5.3 & 12 & $8.1 \%$ & $13.80[7.47,20.13]$ & \\
\hline macroalbuminuria & 17.9 & 14.1 & 10 & -9.3 & 7.5 & 9 & $5.8 \%$ & $27.20[17.18,37.22]$ & \\
\hline Dussol. 2005 & -7 & 11 & 22 & -5 & 15 & 25 & $7.4 \%$ & $-2.00[-9.46,5.46]$ & D \\
\hline Meloni. 2004 & -5.8 & 1.5 & 40 & -6 & 1.3 & 40 & $11.0 \%$ & $0.20[-0.42,0.82]$ & • \\
\hline Hanasen, 2002 & -3.8 & 3.2 & 38 & -3.9 & 3.9 & 38 & $10.8 \%$ & $0.10[-1.50,1.70]$ & - \\
\hline Pijls. 2002 & -11.6 & 29 & 63 & -14.9 & 32.7 & 68 & $5.5 \%$ & $3.30[-7.27,13.87]$ & \\
\hline Raal. 1994 & 3 & 6.5 & 11 & -8 & 6.4 & 11 & $8.7 \%$ & $11.00[5.61,16.39]$ & \\
\hline Dullart, 1993 & -18 & 12.2 & 14 & -10 & 6 & 16 & $7.6 \%$ & $-8.00[-15.03,-0.97]$ & \\
\hline Zeller, 1991 & -11.8 & 4.5 & 20 & -26 & 5.7 & 15 & $9.9 \%$ & $14.20[10.71,17.69]$ & 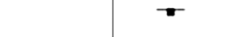 \\
\hline Brouhard. 1990 & -28 & 10 & 8 & -25 & 19.4 & 7 & $3.4 \%$ & $-3.00[-18.95,12.95]$ & \\
\hline Ciavarella. 1990 & 15 & 14.6 & 7 & -11 & 6.2 & 9 & $5.0 \%$ & $26.00[14.45,37.55]$ & \\
\hline Total $(95 \% \mathrm{Cl})$ & & & 308 & & & 316 & $100.0 \%$ & $5.82[2.30,9.33]$ & \\
\hline $\begin{array}{l}\text { Heterogeneity: Tau² } \\
\text { Test for overall effec }\end{array}$ & $\begin{array}{l}2=29 \\
c t: Z=\end{array}$ & $\begin{array}{l}24: \mathrm{Ch} \\
3.24(\end{array}$ & $\mathrm{i}^{2}=1$ & $\begin{array}{l}43.11 . \\
.001)\end{array}$ & $d f=$ & $12(P$ & $<0.0000$ & $01): I^{2}=92 \%$ & 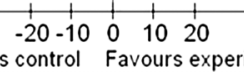 \\
\hline
\end{tabular}

Figure 2 Effects of low-protein diet on glomerular filtration rate.

We conducted sensitivity analyses seeking a pure effect of LPD on diabetic nephropathy. First, we excluded a subgroup of normoalbuminuria patients in the study by Velázquez et $a l^{31}$ since its separate data were provided. The overall improvement was consistent with regard to GFR $\left(6.31,95 \%\right.$ CI 2.47 to $\left.10.15 ; \mathrm{p}<0.00001, \mathrm{I}^{2}=92 \%\right)$ as well as HbAlc $(-0.26,95 \%$ CI -0.34 to -0.17 ; $\left.\mathrm{p}=0.00001, \mathrm{I}^{2}=0 \%\right)$. Subsequently, we excluded an additional three studies that provided combined data of normoalbuminuria and microalbuminuria patients. ${ }^{34} 36 \quad 37$ In this way, patients without diabetic nephropathy were completely eliminated. As a result, improvement of GFR was still significant $(6.32,95 \%$ CI 2.52 to $10.52 ; \mathrm{p}=0.001$, $\left.\mathrm{I}^{2}=93 \%\right)$ and proteinuria improved significantly $(-0.62$, $95 \%$ CI -1.15 to $-0.09 ; \mathrm{p}=0.02, \mathrm{I}^{2}=84 \%$ ).

\section{DISCUSSION}

\section{A statement of the principal findings}

We found a protective effect of dietary intervention by LPD on the course of diabetic nephropathy by improving GFR and proteinuria. In addition, LPD did not worsen either glycaemic control or nutritional status.

\section{Strength and limitations of the study}

Although we searched only English publications, the included numbers of studies and patients were larger than those of any of the previous meta-analyses. Another strength is that we took a unique but reasonable approach to minimise the bias by interstudy difference in patients' compliance to diet treatment. We proposed APIR as the common index that enables the compliance level to be compared across studies. The subgroup analysis based on APIR showed that LPD improved GFR only when intervention was sustainable, which is clinically reasonable.

In addition, APIR was also utilised in the sensitivity analysis of serum albumin, in which three studies with fair diet compliance consistently showed no worsening of nutritional status. Since the number of included

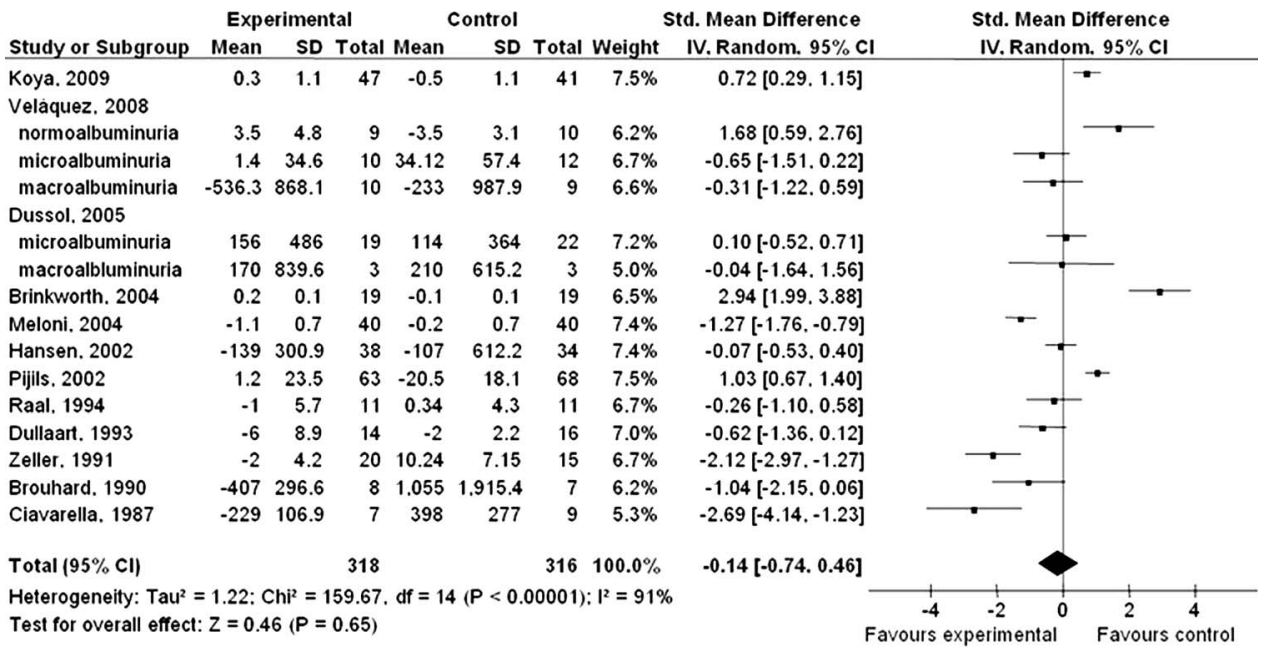

Figure 3 Effects of low-protein diet on proteinuria. 
Table 3 Subgroup analyses and sensitivity analyses for clinical characteristics and study quality

\begin{tabular}{|c|c|c|c|c|c|c|c|c|}
\hline \multirow[b]{2}{*}{ Subgroups } & \multicolumn{4}{|l|}{ GFR } & \multicolumn{4}{|l|}{ Proteinuria } \\
\hline & $\begin{array}{l}\text { Number of } \\
\text { comparisons }\end{array}$ & $\begin{array}{l}\text { Mean difference } \\
(95 \% \mathrm{Cl})\end{array}$ & $I^{2}(\%)$ & p Value* & $\begin{array}{l}\text { Number of } \\
\text { comparisons }\end{array}$ & $\begin{array}{l}\text { Mean difference } \\
(95 \% \mathrm{Cl})\end{array}$ & $I^{2}(\%)$ & p Value* \\
\hline \multicolumn{9}{|l|}{ BMI } \\
\hline Overweight or obese (BMI $\geq 25$ ) & 6 & $6.51(0.29$ to 12.73$)$ & 89 & \multirow[t]{3}{*}{0.57} & 8 & $0.58(-0.13$ to 1.28$)$ & 87 & \multirow{3}{*}{$<0.0001$} \\
\hline Healthy weight (BMI <25) & 3 & $0.82(-11.12$ to 12.76$)$ & 89 & & 3 & $-0.01(-0.91$ to 0.90$)$ & 82 & \\
\hline Unknown & 4 & 9.50 (-1.66 to 20.67$)$ & 96 & & 4 & $-1.64(-2.27$ to -1.01$)$ & 50 & \\
\hline \multicolumn{9}{|l|}{ Type of diabetes } \\
\hline T1DM & 6 & $6.73(-1.45$ to 14.91$)$ & 94 & \multirow[t]{3}{*}{0.05} & 6 & $-1.02(-1.79$ to -0.25$)$ & 81 & \multirow[t]{3}{*}{0.002} \\
\hline T2DM & 5 & $8.63(-0.24$ to 17.50$)$ & 87 & & 6 & $0.88(0.11$ to 1.64$)$ & 88 & \\
\hline Mixed & 2 & $0.19(-0.43$ to 0.80$)$ & 0 & & 3 & $-0.48(-1.57$ to 0.61$)$ & 84 & \\
\hline \multicolumn{9}{|l|}{ Nephropathy stage } \\
\hline $\begin{array}{l}\text { Normoalbuminuria or mix of } \\
\text { normoalbuminuria and } \\
\text { microalbuminuria }\end{array}$ & 2 & $1.81(-1.91$ to 5.53$)$ & 0 & \multirow[t]{4}{*}{0.03} & 3 & 1.83 (0.63 to 3.03 ) & 86 & \multirow[t]{4}{*}{0.001} \\
\hline Microalbuminuria & 2 & 2.96 (-18.41 to 24.32$)$ & 95 & & 3 & $-0.33(-0.84$ to 0.18$)$ & 32 & \\
\hline $\begin{array}{l}\text { Mix of microalbuminuria and } \\
\text { macroalbuminuria }\end{array}$ & 2 & $-2.18(-8.94$ to 4.58$)$ & 0 & & 1 & $-1.04(-2.15$ to 0.06$)$ & - & \\
\hline Macroalbuminuria & 7 & 9.05 (4.30 to 13.81$)$ & 95 & & 8 & $-0.69(-1.45$ to 0.07$)$ & 89 & \\
\hline \multicolumn{9}{|l|}{ Intervention period } \\
\hline Short (6-23 months) $\dagger$ & 7 & 10.52 (3.69 to 17.35$)$ & 92 & \multirow[t]{2}{*}{0.06} & 8 & $-0.18(-1.27$ to 0.91$)$ & 92 & \multirow[t]{2}{*}{0.89} \\
\hline Long ( $\geq 24$ months) & 6 & $1.33(-5.56$ to 8.23$)$ & 92 & & 7 & $-0.09(-0.78$ to 0.60$)$ & 90 & \\
\hline \multicolumn{9}{|l|}{ Overall risk of bias } \\
\hline High (risk score 4-8) & 5 & $3.01(-5.92$ to 11.94$)$ & 85 & \multirow[t]{2}{*}{0.50} & 6 & $-0.16(-1.04$ to 0.71$)$ & 91 & \multirow[t]{2}{*}{0.95} \\
\hline Low (risk score 1-3) & 8 & 6.37 (2.58 to 10.16$)$ & 92 & & 9 & $-0.12(-0.96$ to 0.71$)$ & 91 & \\
\hline \multicolumn{9}{|l|}{ Diet compliance: } \\
\hline Fair (APIR <0.9) & 9 & 8.92 (2.75 to 15.09$)$ & 94 & \multirow[t]{2}{*}{0.006} & 10 & $-0.42(-1.32$ to 0.48$)$ & 91 & \multirow[t]{2}{*}{0.1} \\
\hline Poor (APIR $\geq 0.9$ ) & 4 & $0.03(-1.49$ to 1.56$)$ & 0 & & 5 & $0.43(-0.06$ to 0.93$)$ & 76 & \\
\hline \multicolumn{9}{|l|}{ Measurement index of proteinuria } \\
\hline Proteinuria (g/24 h) & - & - & - & \multirow[t]{4}{*}{-} & 4 & $-0.71(-1.99$ to 0.57$)$ & 94 & \multirow[t]{4}{*}{$<0.00001$} \\
\hline Albuminuria (mg/24 h) & - & - & - & & 7 & $0.26(-0.33$ to 0.85$)$ & 80 & \\
\hline Albuminuria $(\mu \mathrm{g} / \mathrm{min})$ & - & - & - & & 3 & $-1.30(-2.39$ to -0.22$)$ & 67 & \\
\hline \multirow{2}{*}{\multicolumn{9}{|c|}{ Sensitivity analysis }} \\
\hline & & & & & & & & \\
\hline $\begin{array}{l}\text { Excluding a subgroup of } \\
\text { normoalbuminuria with separate } \\
\text { data }\end{array}$ & 12 & 6.31 (2.47 to 10.15$)$ & 92 & & 14 & $-0.26(-0.88$ to 0.36$)$ & 91 & \\
\hline $\begin{array}{l}\text { Excluding studies including } \\
\text { normoalbuminuria }\end{array}$ & 11 & 6.52 (2.52 to 10.52$)$ & 93 & & 12 & $-0.62(-1.15$ to -0.09$)$ & 84 & \\
\hline
\end{tabular}

p Value for subgroup difference.

†Short intervention period was 3-23 months for proteinuria.

APIR, actual protein intake ratio; BMI, body mass index; Cre ratio, creatine ratio; GFR, glomerular filtration rate; T1DM, type 1 diabetes mellitus; T2DM, type 2 diabetes mellitus. 
studies was limited, the interpretation should be cautious. We need another large scale of RCTs to draw more accurate conclusions in terms of this issue on malnutrition.

This study has some more limitations. First, the quality of the evidence assessed for GFR was not high according to the GRADE approach. Two factors that lowered the grade were the inconsistency of the intervention and the indirectness of the outcome. Although the directions of the intervention were consistent across most studies, there was a small overlap in the CIs, and also the heterogeneity was not negligible. This inconsistency may be partly explained by the difference in the study protocol. GFR was measured in different ways in the RCTs included in this meta-analysis, as is also the case in clinical practice. As for the indirectness of outcome, GFR is a candidate surrogate marker to predict kidney failure or initiation of dialysis. However, we should not oversimplify that increasing GFR always represents a better prognosis of the patients' kidney function because glomerular hyperfiltration may occur in early stages of renal damage as postulated by Brenner et $a l_{.}^{45} \mathrm{In}$ addition, the long-term clinical validity of GFR is not sufficient. We hope that more large-scale prospective studies or another meta-analysis will elucidate the effect of LPD on the change in GFR as well as on more long-term clinical outcomes such as mortality, dialysis or transplantation.

The second limitation was the overlaps of nephropathy stages in the subgroup analysis as shown in table 3. Since several studies enrolled patients in more than two stages of nephropathy without reporting the respective separated data, the subgroup analysis could not make clear subgroups without stage overlaps. Therefore, in order to seek a pure effect of LPD in diabetic nephropathy, we conducted sensitivity analyses by removing a subgroup comparison or the studies that included patients free from diabetic nephropathy. The analyses showed a consistently significant improvement in GFR. Although proteinuria was improved differently from the overall analysis, it is reasonable in two ways. First, it is logically impossible to reduce albuminuria in patients who have not suffered from albuminuria. Second, the relation is clinically compatible between reduction of proteinuria and improvement in kidney function.

The third limitation was that a part of the missing information for outcome was imputed, generating a risk of heterogeneity. We estimated unknown SDs by using the correlation coefficient obtained from included studies in this meta-analysis. However, the correlation coefficient was drawn from a study or a subgroup of macroalbuminuria. ${ }^{31} 32$ Therefore, this estimation might not have been proper substitutes for studies or subgroups of patients with normoalbuminuria or microalbuminuria. Sensitivity analysis excluding the study that enrolled patients with normoalbuminuria still includes microalbuminuric patients, and thus the interpretation should be cautious.

\section{Comparison with other studies}

There are three meta-analyses on this issue pooling the data from RCTs. The meta-analysis by Pedrini et $a l^{14}$ reported the beneficial effects of LPD; however, they combined RCTs and non-randomised crossover trials. In addition, they used a composite outcome of GFR or albuminuria. The meta-analyses by Pan et $a l^{12}$ and Robertson $e t a l^{13}$ did not show significant effects on kidney function. The different result is explainable by the difference in the pooled study number and population size. The meta-analysis by Robertson et al especially have pooled the data from only seven RCTs, since they focused on a study including T1DM patients. Consistently, in our analysis, GFR in T1DM patients was improved but not statistically significantly.

Pan et als meta-analysis included two reports by Pijls et al. ${ }^{37}$ However, the patient's background in these two reports was almost identical as shown in table 1 . What was different was the number of patients and the intervention period, which was large and longer in a recent publication. Our reviewers discussed in the committee and concluded that the previous publication might be the interim analysis of a longer project. Therefore, although both these studies are listed in our meta-analysis, their results are not used simultaneously in the same outcome analysis. We extracted data on GFR and albuminuria from the recent publication. Data on HbAlc was extracted from the previous publication since it was not reported in the recent one. We believe this strategy will not interfere with excluding the duplicate publication bias as warned in section 10.2.2.1. of the Cochrane Handbook for Systematic Reviews of Interventions V.5.1.0. ${ }^{18}$

Another difference between our study and Pan $e t a l \mathrm{~s}$ meta-analysis is that we added two newly conducted RCTs by Koya $e t a l^{15}$ and Velázquez et al. ${ }^{31}$ However, the level of $24 \mathrm{~h}$ UUN was 1 in the study by Koya $e t a l$, which was no less than that in the control group (APIR=1). In addition, the intervention period of the study by Velázquez et al was only 4 months, which might be insufficient to detect the change in GFR as discussed by Zeller et $a l^{40}$ We need more large-scale RCTs of sufficient length and sufficiently compliant for more conclusive evidence regarding the effect of LPD on GFR.

\section{Messages for clinicians}

This meta-analysis showed that LPD improved the kidney function of patients with diabetic nephropathy only when their diet compliance was fair. This finding lets clinicians reaffirm the importance of long-term sustainability of dietary intervention. We think we are quite aware of the importance, but we have also been experiencing the challenge presented by this task. However, this study result showed that the protein restriction need not be as stringent as we have been thinking. The cut-off value of APIR for fair compliance was 0.9 in this study, which was modest compared with the current clinical 
guideline. ${ }^{11}$ This finding casts a new light on our management of diet treatment.

\section{Conclusion and future research}

A diet intervention by LPD has modest but significant effects on the course of kidney prognosis in patients with diabetic nephropathy, especially when the intervention is sustainable regarding patients' compliance. This result of meta-analysis questions whether LPD prevents or delays more important clinical outcomes such as kidney failure, initiation of dialysis and death. Further meta-analyses that focus on these outcomes are needed.

\section{Author affiliations}

${ }^{1}$ Department of Clinical Pharmacology \& Therapeutics, University of the Ryukyus, Okinawa, Japan

${ }^{2}$ Department of Endocrinology \& Metabolism, Yokohama City University Graduate School of Medicine, Kanagawa, Japan

${ }^{3}$ Department of Endocrinology \& Metabolism, Chigasaki Municipal Hospital, Kanagawa, Japan

${ }^{4}$ Department of Internal Medicine, Hyogo College of Medicine, Hyogo, Japan

Contributors UN had the idea for the study and designed the method of this meta-analysis including the inclusion and exclusion criteria, conducted data collection and extraction, wrote the first draft of the report and did the statistical analysis with guidance from MS and TM. UN and HK searched the articles and assessed their eligibility. When discrepancies occurred, the eligibility of the articles was discussed by the committee consisting of UN, MS, TM and SU. TM did the major revision and also made comments. All other authors commented on the draft and approved the final version of the manuscript. UN and SU are the guarantors.

Funding This research received no specific grant from any funding agency in the public, commercial or not-for-profit sectors.

Competing interests None.

Provenance and peer review Not commissioned; externally peer reviewed.

Data sharing statement No additional data are available.

\section{REFERENCES}

1. The Diabetes Control and Complications Trial Research Group. The effect of intensive treatment of diabetes on the development and progression of long-term complications in insulin-dependent diabetes mellitus. N Engl J Med 1993;329:977-86.

2. Retnakaran R, Cull CA, Thorne KI, et al. Risk factors for renal dysfunction in type 2 diabetes: U.K. Prospective Diabetes Study 74. Diabetes 2006:55:1832-9.

3. Valmadrid CT, Klein R, Moss SE, et al. The risk of cardiovascular disease mortality associated with microalbuminuria and gross proteinuria in persons with older-onset diabetes mellitus. Arch Inter Med 2000;160:1093-100.

4. Ritz E, Orth SR. Nephropathy in patients with type 2 diabetes mellitus. N Engl J Med 1999;341:1127-33.

5. Gordois A, Scuffham P, Shearer A, et al. The health care costs of diabetic nephropathy in the United States and the United Kingdom. J Diabetes Complications 2004;18:18-26.

6. Group UPDSU. Intensive blood-glucose control with sulphonylureas or insulin compared with conventional treatment and risk of complications in patients with type 2 diabetes (UKPDS 33). Lancet 1998;352:837-53.

7. Intensive blood glucose control and vascular outcomes in patients with type 2 diabetes-NEJM. http://www.nejm.org/doi/full/10.1056/ NEJMoa0802987 (accessed 13 Dec 2012).

8. Effects of losartan on renal and cardiovascular outcomes in patients with type 2 diabetes and nephropathy-NEJM. http://www.nejm.org/ doi/full/10.1056/NEJMoa011161 (accessed 13 Dec 2012).

9. Lewis EJ, Hunsicker LG, Bain RP, et al. The effect of angiotensin-converting-enzyme inhibition on diabetic nephropathy. The Collaborative Study Group. N Engl J Med 1993;329:1456-62.
10. Molitch ME, DeFronzo RA, Franz MJ, et al. Diabetic nephropathy. Diabetes Care 2003;26(Suppl 1):S94-8.

11. American Diabetes Association. Standards of medical care in diabetes-2013. Diabetes Care 2012;36:S11-66.

12. Pan Y, Guo LL, Jin HM. Low-protein diet for diabetic nephropathy: a meta-analysis of randomized controlled trials. Am J Clin Nutr 2008;88:660-6.

13. Robertson L, Waugh N, Robertson A. Protein restriction for diabetic renal disease. Cochrane Database Syst Rev 2007;4: CD002181.

14. Pedrini MT, Levey AS, Lau J, et al. The effect of dietary protein restriction on the progression of diabetic and nondiabetic renal diseases: a meta-analysis. Ann Intern Med 1996;124:627-32.

15. Koya D, Haneda M, Inomata S, et al. Long-term effect of modification of dietary protein intake on the progression of diabetic nephropathy: a randomised controlled trial. Diabetologia 2009;52:2037-45.

16. Moher $\mathrm{D}$, Liberati $\mathrm{A}$, Tetzlaff $\mathrm{J}$, et al. Preferred reporting items for systematic reviews and meta-analyses: the PRISMA statement. BMJ 2009;339:b2535.

17. Seino Y, Nanjo K, Tajima N, et al. Report of the Committee on the Classification and Diagnostic Criteria of Diabetes Mellitus. Diabetol Int 2010;1:2-20.

18. Cochrane Handbook for Systematic Reviews of Interventions. http:// handbook.cochrane.org/ (accessed 11 Dec 2012).

19. Follmann D, Elliott $\mathrm{P}$, Suh I, et al. Variance imputation for overviews of clinical trials with continuous response. $J$ Clin Epidemiol 1992:45:769-73.

20. Abrams KR, Gillies CL, Lambert PC. Meta-analysis of heterogeneously reported trials assessing change from baseline. Stat Med 2005;24:3823-44.

21. Balshem $\mathrm{H}$, Helfand $\mathrm{M}$, Schünemann $\mathrm{HJ}$, et al. GRADE guidelines: 3. Rating the quality of evidence. J Clin Epidemiol 2011;64:401-6.

22. Guyatt GH, Oxman AD, Vist G, et al. GRADE guidelines: 4. Rating the quality of evidence-study limitations (risk of bias). J Clin Epidemiol 2011;64:407-15.

23. Narita T, Koshimura J, Meguro $\mathrm{H}$, et al. Determination of optimal protein contents for a protein restriction diet in type 2 diabetic patients with microalbuminuria. Tohoku J Exp Med 2001;193:45-55.

24. Sugimoto T, Kikkawa R, Haneda M, et al. Effect of dietary protein restriction on proteinuria in non-insulin-dependent diabetic patients with nephropathy. J Nutr Sci Vitaminol (Tokyo) 1991;37(Suppl): S87-92.

25. Giordano M, Lucidi P, Ciarambino T, et al. Effects of dietary protein restriction on albumin and fibrinogen synthesis in macroalbuminuric type 2 diabetic patients. Diabetologia 2008;51:21-8.

26. Percheron C, Colette C, Astre C, et al. Effects of moderate changes in protein intake on urinary albumin excretion in type I diabetic patients. Nutrition 1995;11:345-9.

27. Walker JD, Bending JJ, Dodds RA, et al. Restriction of dietary protein and progression of renal failure in diabetic nephropathy Lancet 1989;2:1411-15.

28. Pedersen MM, Mogensen CE, Jørgensen FS, et al. Renal effects from limitation of high dietary protein in normoalbuminuric diabetic patients. Kidney Int Suppl 1989;27:S115-21.

29. Hansen HP, Christensen PK, Tauber-Lassen E, et al. Low-protein diet and kidney function in insulin-dependent diabetic patients with diabetic nephropathy. Kidney Int 1999;55:621-8.

30. Meloni C, Morosetti M, Suraci C, et al. Severe dietary protein restriction in overt diabetic nephropathy: benefits or risks? J Ren Nutr 2002;12:96-101.

31. Velázquez López L, Sil Acosta MJ, et al. Effect of protein restriction diet on renal function and metabolic control in patients with type 2 diabetes: a randomized clinical trial. Nutr Hosp 2008;23:141-7.

32. Dussol B, lovanna C, Raccah D, et al. A randomized trial of low-protein diet in type 1 and in type 2 diabetes mellitus patients with incipient and overt nephropathy. J Ren Nutr 2005;15: 398-406.

33. Meloni C, Tatangelo P, Cipriani S, et al. Adequate protein dietary restriction in diabetic and nondiabetic patients with chronic renal failure. J Ren Nutr 2004:14:208-13.

34. Brinkworth GD, Noakes M, Parker B, et al. Long-term effects of advice to consume a high-protein, low-fat diet, rather than a conventional weight-loss diet, in obese adults with type 2 diabetes: one-year follow-up of a randomised trial. Diabetologia 2004:47:1677-86.

35. Hansen HP, Tauber-Lassen E, Jensen BR, et al. Effect of dietary protein restriction on prognosis in patients with diabetic nephropathy. Kidney Int 2002;62:220-8.

36. Pijls LTJ, De Vries H, Van Eijk JTM, et al. Protein restriction, glomerular filtration rate and albuminuria in patients with type 2 
diabetes mellitus: a randomized trial. Eur $J$ Clin Nutr 2002;56:1200-7.

37. Pijls LT, De Vries H, Donker AJ, et al. The effect of protein restriction on albuminuria in patients with type 2 diabetes mellitus: a randomized trial. Nephrol Dial Transplant 1999;14:1445-53.

38. Raal FJ, Kalk WJ, Lawson M, et al. Effect of moderate dietary protein restriction on the progression of overt diabetic nephropathy: a 6-mo prospective study. Am J Clin Nutr 1994;60:579-85.

39. Dullaart RP, Beusekamp BJ, Meijer S, et al. Long-term effects of protein-restricted diet on albuminuria and renal function in IDDM patients without clinical nephropathy and hypertension. Diabetes Care 1993;16:483-92.

40. Zeller K, Whittaker E, Sullivan L, et al. Effect of restricting dietary protein on the progression of renal failure in patients with insulin-dependent diabetes mellitus. N Engl J Med 1991;324:

78-84.

41. Ciavarella A, Di Mizio G, Stefoni S, et al. Reduced albuminuria after dietary protein restriction in insulin-dependent diabetic patients with clinical nephropathy. Diabetes Care 1987;10:407-13.

42. Brouhard $\mathrm{BH}$, Lagrone $\mathrm{L}$. Effect of dietary protein restriction on functional renal reserve in diabetic nephropathy. Am J Med 1990;89:427-31.

43. Maroni BJ, Steinman TI, Mitch WE. A method for estimating nitrogen intake of patients with chronic renal failure. Kidney Int 1985;27:58-65.

44. Bingham SA. Urine nitrogen as a biomarker for the validation of dietary protein intake. J Nutr 2003;133(Suppl):921S-4S.

45. Brenner BM, Lawler EV, Mackenzie HS. The hyperfiltration theory: a paradigm shift in nephrology. Kidney Int 1996;49:1774-7. 